\title{
AVALIAÇÃO DA DIVULGAÇÃO DE FATOS RELEVANTES NO CASO KROTON E ESTÁCIO DE SÁ: UM ESTUDO DE EVENTOS
}

\author{
EVALUATION OF THE RELEVANT FACTS' DISCLOSURE IN KROTON-ESTÁCIO DE SÁ \\ CASE: AN EVENTS STUDY
}

\author{
Aléxica Dias de Freitas Alves ${ }^{1}$ \\ Universidade Federal de Minas Gerais \\ alexicadias@msn.com \\ https://orcid.org/0000-0003-4965-7401
}

\author{
Glaysson Aguilar De Araújo \\ Universidade Federal de Minas Gerais \\ glayssonaraujo@yahoo.com.br \\ https://orcid.org/0000-0002-7774-2227
}

\author{
Poueri do Carmo Mário \\ Universidade Federal de Minas Gerais \\ poueri@gmail.com \\ https://orcid.org/0000-0003-4307-6040
}

\section{RESUMO}

O objetivo do estudo foi identificar os efeitos provocados no preço das ações das instituições educacionais brasileiras Kroton e Estácio de Sá em função da divulgação de fatos relevantes acerca de uma potencial combinação de negócios. O CADE reprovou a operação em 28/06/2017, mais de um ano após a divulgação do primeiro fato relevante que havia ocorrido em 02/06/2016. Por meio de um Estudo de Eventos, foram calculados e analisados os retornos anormais das ações das instituições nos dois momentos supracitados. No geral, os resultados demonstraram um efeito positivo, mas pontual, de aproximadamente $33 \%$ no momento $t_{0}$ na janela de eventos do Evento I, essa janela gerou Retorno Anormal Acumulado em 32\% para o Modelo de Ajuste ao Mercado e em 51\% para o Ajustado ao Risco e Mercado. No Evento II, o efeito positivo foi de $5 \%$, não sendo suficiente para manter um resultado positivo na acumulação dos retornos dentro da janela. Destaca-se a demora no parecer final do CADE que pode ter influenciado e ser uma explicação do comportamento dos preços dos ativos.

Palavras-Chave: Combinação de Negócios. Fatos Relevantes. Estudo de Eventos.

\section{ABSTRACT}

The objective of the study was to identify the effects on the stock priceof the Brazilian educational institutions Kroton and Estácio de Sá due to the disclosure of relevant facts about a potential business combination. CADE disapproved the operation on June,28/2017, more than a year after the disclosure of the first material fact that had occurred on June, 02/2016.

\footnotetext{
${ }^{1}$ Rua Carlos Turner, 111 Bloco 1 Apto 104 - Silveira, Belo Horizonte - MG, CEP 31.140-520.
} 
Using the event study methodology, abnormal returns on the actions of the institutions were calculated and analyzed at the two aforementioned moments. Overall, the results showed a positive but punctual effect of approximately $33 \%$ at time $t_{0}$ in the event window of Event I; this window generated a 32\% accumulated abnormal returns for the Market Adjustment Model and $51 \%$ for the Risk and Market Adjusted Model. In Event II, the positive effect was 5\%, which is not enough to maintain a positive result in the accumulation of returns within the window. The delay in CADE's final opinion is highlighted, which may have influenced and be an explanation of the behavior of asset prices.

Keywords: Business Combination. Relevant Facts. Event study.

\section{INTRODUÇÃO}

O setor de educação enfrentou em 2016 um quadro de estagnação de matrículas no ensino superior, sendo argumentado como justificativa a crise econômica pela qual o país passou. Conforme veiculado em mídia de grande notoriedade, o Estadão, dados do Censo da Educação Superior de 2016 apontaram registros de 8,05 milhões de matrículas em cursos de nível superior naquele ano, frente à 8,03 milhões de matrículas em 2015, representando uma variação de apenas $0,2 \%$. Ademais, pela primeira vez em 11 anos, os dados elucidados pelo Censo apontaram que o número de alunos na rede particular de ensino superior havia diminuído no Brasil.

Dentro desse contexto de retração de mercado devido à conjuntura econômica que o Brasil vivenciava, as instituições de ensino superior privado buscaram alternativas para se manterem competitivas. Nesse sentido, a Kroton Educacional S.A. (Kroton), agora Cogna Educação S.A, a maior empresa de educação e ensino do País (Valor Econômico, 2021), pleiteou um processo de combinação de negócios com a Estácio Participações S.A. (Estácio), que assumia a segunda posição no ranking das 1000 Maiores Empresas do setor (Valor Econômico, 2021). Tal fato foi comunicado ao mercado aos dois dias de junho de 2016, mesmo período no qual o setor de educação sofria com os reflexos da crise econômica. Essa combinação criaria um dos maiores grupos educacionais do mundo.

Melo, Tinoco e Yoshitake (2012) destacam que operações de combinações de negócios estão entre as mais importantes maneiras de alterações organizacionais, dado que são caracterizadas pela obtenção do controle por parte de uma companhia investidora sobre uma ou mais sociedades investidas ou pela efetiva junção de dois grupos independentes.

A Kroton destacou que uma potencial combinação de negócios traria benefícios para ambas as empresas, seus negócios, alunos, acionistas e demais stakeholders. Gitman (2004) destaca que o principal objetivo das operações de alterações societárias é a maximização de riqueza dos donos, o que se reflete no preço das ações das empresas compradoras.

A combinação de negócios proposta pela Kroton foi de grande materialidade no mercado, sendo avaliada, conforme dados do website Infomoney, em R \$ 5,5 bilhões. No entanto, o CADE (Conselho Administrativo de Defesa Econômica), entidade responsável, no âmbito do Poder Executivo, por decidir, em última instância, sobre a matéria concorrencial, reprovou, por 5 votos a 1, a fusão de Kroton e Estácio. Tal negativa ocorreu em 28 de junho de 2017, há mais de um ano da divulgação do primeiro fato relevante que, outrora, havia ocorrido em 02 de junho de 2016.

Nesse sentido, o presente trabalho pretende analisar quais os efeitos nos papéis dessas duas empresas, diante das notícias ou informações publicadas ao mercado (fatos relevantes), durante o processo dessa tentativa de combinação de negócios, e, assim, verificar como o mercado, no caso, o mercado acionário, reagiu durante as divulgações que ocorreram. 
Portanto, assumindo que o mercado acionário reage à medida que novas informações relevantes são divulgadas em domínios públicos, a pergunta que motiva essa pesquisa é: "quais os efeitos nos preços dos papéis das instituições Kroton e Estácio, durante todo o período do processo da combinação de negócios pleiteada?".

O objetivo desse estudo foi, por meio da avaliação de fatos relevantes, analisar o evento do primeiro fato relevante divulgado ao mercado até o último fato comunicado (negativa do CADE para a operação de fusão), avaliando os efeitos sobre os retornos anormais nas ações de ambas as instituições de ensino.

No que tange à justificativa para essa pesquisa se destaca que, num cenário cada vez mais dinâmico e com a velocidade da informação, as empresas e o mercado precisam sempre estar atentos a todos os fatos inerentes de novos eventos. Nakayama (2012) destaca que fusões e aquisições é um fenômeno que envolve altas cifras em transações e que uma pesquisa focada na divulgação sobre tal fenômeno que, por sua vez, afeta a vida das empresas e decisões de investidores, de trabalhadores e de governo, tende a contribuir para uma melhor compreensão dessas complexas operações.

Ademais, na busca constante por criação de valor aos acionistas, torna-se essencial analisar o comportamento do mercado diante de uma operação com esse objetivo.

Outro ponto importante a ser destacado está na hipótese de eficiência de mercado, que pressupõe a análise da velocidade e qualidade, direção e magnitude do ajustamento dos preços às novas informações" (Camargos \& Barbosa, 2015). O trabalho aqui desenvolvido buscou contribuir ao testar a hipótese de eficiência de mercado, uma vez que analisou os efeitos dos eventos divulgados ao mercado.

Em completude, denota-se que por se tratar de uma pesquisa que analisou um caso recente ocorrido no Brasil, não foram encontrados na literatura estudos acerca da tentativa de combinação de negócios da Kroton e da Estácio. O foco nessas instituições se justifica, ainda, pelo contexto que o setor de educação vem enfrentando nos últimos anos decorrente da crise econômica vivenciada no país, o que corrobora a relevância de se analisar uma operação que criaria, no setor, um dos maiores grupos educacionais do mundo, como já enfatizado.

O trabalho foi estruturado da seguinte maneira: i) no tópico 2 apresenta-se o referencial teórico, abrangendo os temas combinação de negócios, causas e motivações, recentes contribuições ao assunto e o caso Kroton; ii) o tópico 3 trará a metodologia empregada na pesquisa; iii) o tópico 4 abordará a análise e discussão dos resultados e iv) o tópico 5 irá apresentar as considerações finais.

\section{REVISÃO DA LITERATURA E ESTUDOS}

\subsection{Combinação de Negócios}

Os aspectos societários de uma combinação de negócios são abordados na legislação societária - Lei 6.404/76 e nas regulamentações da Comissão de Valores Mobiliários (CVM), enquanto os aspectos contábeis têm como base o Pronunciamento Técnico CPC 15 Combinações de Negócios.

À luz do CPC 15, define-se a combinação de negócios como "uma operação ou outro evento por meio do qual um adquirente obtém o controle de um ou mais negócios, independentemente da forma jurídica da operação". Diretamente, a definiçãa não trata sobre os modelos e as formas jurídicas deste tipo de operação (fusão, incorporação ou cisão), mas sim, postula a obtenção do controle como determinante no processo. Gelbcke, Santos, Iudícibus e Martins (2021) enfatizam que a obtenção do controle de um ou mais negócios pode ocorrer por diferentes meios, tais como a aquisição de um conjunto de ativos líquidos de outra empresa que 
constituem um negócio, ou a maneira que ela venha a ter poder sobre as decisões da investida em seu próprio benefício.

A Lei Societária 6.404/76 define:

- INCORPORAÇÃO: "é a operação pela qual uma ou mais sociedades são absorvidas por outra, que lhes sucede em todos os direitos e obrigações". (Art. 227)

- $\quad$ FUSÃO: "é a operação pela qual se unem duas ou mais sociedades para formar sociedade nova, que lhes sucederá em todos os direitos e obrigações”. (Art. 228)

- CISÃO: "é a operação pela qual a companhia transfere parcelas do seu patrimônio para uma ou mais sociedades, constituídas para esse fim ou já existentes, extinguindo-se a companhia cindida, se houver versão de todo o seu patrimônio, ou dividindo-se o seu capital, se parcial a versão". (Art. 229)

Gelbcke et al. (2021) corroboram que, então, aquisições, incorporações e fusões e outras formas de reorganização societárias serão consideradas como combinação de negócio, para fins contábeis, se, e somente se, houver obtenção de controle de um ou mais negócios, dos quais não se detinha antes o mesmo (controle).

\subsection{Causas e Motivações}

Com uma crescente competitividade entre as empresas inseridas no contexto globalizado, torna-se imprescindível a busca por meios que minimizem os custos operacionais e agilizem todo o processo organizacional.

A Tabela 1 apresenta os principais motivos para as fusões e aquisições referenciados por Camargos e Barbosa (2005), por meio de pesquisa na literatura econômico-financeira.

Tabela 1. Motivos para fusões e aquisições

\begin{tabular}{c|c}
\hline Expectativas Assimétricas & $\begin{array}{c}\text { Diferentes expectativas sobre o futuro levam os investidores a } \\
\text { atribuírem valores diferentes a uma mesma firma, ocasionando } \\
\text { propostas de compra. }\end{array}$ \\
$\begin{array}{c}\text { Compensações e Incentivos } \\
\text { Tributários }\end{array}$ & $\begin{array}{c}\text { Advindos de créditos tributários, relativos à compensação de prejuízos } \\
\text { acumulados por uma das empresas envolvidas nos lucros de exercícios } \\
\text { futuros da outra firma, conforme percentuais autorizados pela legislação } \\
\text { brasileira. }\end{array}$ \\
$\begin{array}{c}\text { Custos de Reposição e Valores de } \\
\text { Mercado }\end{array}$ & $\begin{array}{c}\text { Situação existente quando os custos de reposição dos ativos de uma } \\
\text { firma forem maiores que o seu valor de mercado; isto é, quando a razão } \\
\text { "Q de Tobin” (valor de mercado / valor patrimonial) de uma da firma } \\
\text { for menor do que a unidade ("Q de Tobin” < 1). }\end{array}$ \\
$\begin{array}{c}\text { Busca de Economias de Escala } \\
\text { Sinergias Operacionais e } \\
\text { Gerenciais) }\end{array}$ & $\begin{array}{c}\text { Advindas de possíveis reduções nos custos em função do aumento do } \\
\text { nível de produção, maior racionalização do esforço de pesquisa e } \\
\text { desenvolvimento, uso conjunto de insumos específicos não divisíveis e } \\
\text { transferência de tecnologia e conhecimento (know-how) }\end{array}$ \\
\hline $\begin{array}{c}\text { Efeitos Anticompetitivos e Busca do } \\
\text { Poder de Monopólio }\end{array}$ & $\begin{array}{c}\text { Advindos de ganhos com o aumento da concentração de mercado e da } \\
\text { consequente redução da competição. }\end{array}$ \\
\hline $\begin{array}{c}\text { Redução do Risco de Insolvência } \\
\text { Advinda da fusão entre duas ou mais firmas com fluxos de caixa sem } \\
\text { correlação perfeita (F\&As conglomerado e co-seguro). }\end{array}$
\end{tabular}

Nota. Fonte: Recuperado de "Análise do desempenho econômico-financeiro e da criação de sinergias em processos de fusão e aquisição do mercado brasileiro ocorrido entre 1995 e 1999”, de M. A. Camargos e F. D. Barbosa, 2005.

Além dos motivos listados, é razoável pensar que fusões e aquisições são formas de alcançar algum tipo de sinergia, aumentando assim, a eficiência da economia como um todo, segundo Martelanc (2010). 
Para Melo (2010), as técnicas de combinação de negócios estão entre as mais relevantes ferramentas para o crescimento e expansão econômica das empresas.

\subsection{Contribuições ao Assunto}

A expressividade do estudo desse tema ganhou cenários cada vez mais atuantes. Calil, Bueno, Domingues e Borges (2020) encontraram evidências de quatro agrupamentos temáticos nas produções acadêmicas sobre fusões e aquisições em seu estudo, a saber: economia/finanças, estratégia, gestão do processo de fusões e aquisições e aspectos culturais.

Segundo os autores, há uma predominância nas temáticas economia/finanças e estratégia, que são constituídas por artigos que abordam, dentre outros temas: desempenho econômico-financeiro, sinergia, criação de valor para os acionistas, receptividade do mercado, rentabilidade das ações, crescimento das organizações e criação de vantagens competitivas (Calil et al., 2020).

Neste contexto, na Tabela 2 estão algumas contribuições nacionais desde 2016.

Tabela 2. Pesquisas nacionais recentes

\begin{tabular}{|c|c|c|}
\hline Autores & Objetivo & Conclusão \\
\hline $\begin{array}{l}\text { Macohon, Zittei e Klann } \\
\text { (2016) }\end{array}$ & $\begin{array}{c}\text { Analisar a variância dos } \\
\text { indicadores de desempenho de } 47 \\
\text { empresas com ações negociadas } \\
\text { na BM\&FBOVESPA que } \\
\text { passaram por operações de } \\
\text { combinação de negócios no ano } \\
\text { de } 2010 .\end{array}$ & $\begin{array}{c}\text { A partir dos índices de desempenho } \\
\text { analisados, as variáveis não apresentaram } \\
\text { variância significativa para o fator Ano no } \\
\text { período de análise. A variável ROA } \\
\text { apresentou variância significativa para o } \\
\text { fator Setor. A ANOVA parte do pressuposto } \\
\text { que o acaso produz pequenos desvios, as } \\
\text { maiores diferenças são causadas por fatos } \\
\text { reais, neste caso as F\&A. Assim, não é } \\
\text { possível afirmar que estas variações } \\
\text { ocorreram em função das } \\
\text { F\&A. }\end{array}$ \\
\hline $\begin{array}{c}\text { Vieira, Brito, Santana, } \\
\text { Sanches e Galdamez } \\
\text { (2017) }\end{array}$ & $\begin{array}{l}\text { Analisar se há diferenças nos } \\
\text { indicadores de liquidez, } \\
\text { rentabilidade e alavancagem das } \\
\text { empresas brasileiras de capital } \\
\text { aberto que efetuaram operações } \\
\text { de fusões e aquisições de } 2010 \text { a } \\
2014 \text {. }\end{array}$ & $\begin{array}{l}\text { Os principais resultados apontam que, em } \\
\text { curto prazo, há uma pioria dos indicadores } \\
\text { de liquidez provocada principalmente pelo } \\
\text { aumento da necessidade de capital de giro, } \\
\text { com diferença estatística significante. Já para } \\
\text { a rentabilidade e alavancagem essa diferença } \\
\text { não foi confirmada. Conclui-se que essa } \\
\text { piora é tempestiva ao período imediato à } \\
\text { operação de aquisição e fusão, podem ser } \\
\text { restabelecidas a situação financeira e a } \\
\text { rentabilidade em períodos subsequentes se a } \\
\text { sinergia operacional e financeira for } \\
\text { atingida. }\end{array}$ \\
\hline Eloy e De Souza (2018) & $\begin{array}{l}\text { Identificar as características dos } \\
\text { ativos intangíveis reconhecidos } \\
\text { nas combinações de negócios e } \\
\text { sua relação com as características } \\
\text { das companhias de capital aberto } \\
\text { brasileiras no período entre } 2012 \\
\text { e } 2014 \text {. }\end{array}$ & $\begin{array}{l}\text { Quanto aos resultados, dos setores de } \\
\text { atuação, o setor de consumo cíclico foi o que } \\
\text { apresentou o maior número de companhias } \\
\text { dentre as que realizaram combinações de } \\
\text { negócios no período analisado. Quanto ao } \\
\text { nível de governança corporativa, a maioria } \\
\text { das companhias classificadas em algum } \\
\text { nível diferenciado reconheceram goodwill, } \\
\text { enquanto mais da metade das companhias } \\
\text { sem classificação diferenciada de } \\
\text { governança corporativa não reconheceram } \\
\text { goodwill. }\end{array}$ \\
\hline
\end{tabular}




\begin{tabular}{|c|c|c|}
\hline $\begin{array}{c}\text { Toigo, Hein e Kroenke } \\
\text { (2018) }\end{array}$ & $\begin{array}{l}\text { Identificar as características } \\
\text { predominantes de governança } \\
\text { corporativa e desempenho das } \\
\text { companhias que realizaram } \\
\text { fusões e aquisições com troca de } \\
\text { controle no período de } 2006 \text { a } \\
2010 \text {. }\end{array}$ & $\begin{array}{l}\text { O desempenho superior das companhias } \\
\text { pelos Filtros de Graham, aliado ao } \\
\text { incremento de alguns mecanismos } \\
\text { específicos de governança corporativa, tende } \\
\text { a auxiliar no monitoramento dos gestores } \\
\text { pelos acionistas, que contribuem para o } \\
\text { alinhamento de interesses do principal e do } \\
\text { agente, reduzindo os problemas de agência } \\
\text { após as fusões e aquisições. }\end{array}$ \\
\hline $\begin{array}{l}\text { Fasolin, Brizolla, Silva e } \\
\text { Klann (2019) }\end{array}$ & $\begin{array}{l}\text { Identificar as características de } \\
\text { governança corporativa e } \\
\text { econômico-financeiras que } \\
\text { influenciam as práticas de } \\
\text { combinação de negócios em } \\
\text { empresas brasileiras. }\end{array}$ & $\begin{array}{l}\text { Pode-se inferir que as características de } \\
\text { governança corporativa presente nas } \\
\text { empresas não influenciam na realização das } \\
\text { práticas de combinação de negócios. } \\
\text { Dentre as variáveis financeiras das empresas } \\
\text { (tamanho, endividamento, rentabilidade e } \\
\text { liquidez), o resultado do modelo de } \\
\text { regressão logística apontou o tamanho das } \\
\text { organizações, medido pelo logaritmo do } \\
\text { ativo total, como a característica mais } \\
\text { significativa que explica as transações de } \\
\text { combinação de negócios. }\end{array}$ \\
\hline $\begin{array}{l}\text { Silva, Souza, Avelino e } \\
\text { Pinheiro (2020) }\end{array}$ & $\begin{array}{l}\text { Analisar de que forma a } \\
\text { divulgação da informação de } \\
\text { perda por redução ao valor } \\
\text { recuperável do goodwill, } \\
\text { influencia os preços das ações. }\end{array}$ & $\begin{array}{l}\text { O mercado de ações reage às perdas por } \\
\text { impairment registradas pelas empresas. E, } \\
\text { quanto maior o lucro e mais ativos que } \\
\text { gerem expectativa de rentabilidade futura as } \\
\text { companhias tiverem, mais valorizadas elas } \\
\text { serão no mercado de capitais. }\end{array}$ \\
\hline $\begin{array}{c}\text { Fogaça, Souza, Oliveira e } \\
\text { Silva }(2020)\end{array}$ & $\begin{array}{l}\text { Realizar um levantamento } \\
\text { exploratório acerca das principais } \\
\text { informações quanto à } \\
\text { integralidade da divulgação dos } \\
\text { ativos identificáveis reconhecidos } \\
\text { presentes nos relatórios } \\
\text { financeiros vinte e oito entidades } \\
\text { envolvidas em combinações de } \\
\text { negócios realizadas em } 2017\end{array}$ & $\begin{array}{l}\text { Os resultados apontam um percentual de } \\
\text { divulgação dos ativos intangíveis } \\
\text { identificáveis de metade das informações } \\
\text { que o CPC } 15 \text { sugere. A parcela de empresas } \\
\text { que não divulga tais informações podem } \\
\text { estar relacionada com o pressuposto de } \\
\text { julgamento dos gestores ao avaliarem que o } \\
\text { custo de se gerar tal informação, de forma } \\
\text { completa, não supera o benefício a ela } \\
\text { desejado. }\end{array}$ \\
\hline
\end{tabular}

\subsection{O Caso Kroton-Estácio}

Fundada em 1966, em uma sala de aula de Belo Horizonte, MG, inicialmente como o curso pré-vestibular Pitágoras, a rede Kroton de Ensino tornou-se ao longo dos anos a maior empresa de educação e ensino do País, presente no topo do ranking das 1000 Maiores Empresas do setor (Valor Econômico, 2021). A abertura de capital do Pitágoras ocorreu no ano de 2007, com o nome de Kroton Educacional, vindo a se tornar Cogna Educação em 2019.

Por sua vez, a rede de ensino Estácio de Sá foi fundada em 1970, em uma pequena casa na zona norte do Rio de Janeiro, com a criação da Faculdade de Direito Estácio de Sá. Ao longo dos anos a Estácio também expandiu suas operações e, assim como a Kroton, realizou a abertura de capital no ano de 2007. Assumiu a segunda posição no ranking das 1000 Maiores Empresas do setor (Valor Econômico, 2021).

Nesse contexto, a Kroton divulgou fato relevante ao mercado em 02 de junho de 2016 para esclarecer divulgação na mídia acerca de uma potencial combinação de negócios com a Estácio. O interesse foi ratificado em 21 de junho de 2016, com a divulgação de novo fato relevante ao mercado, no qual a Kroton enviou uma carta do Conselho de Administração da Estácio corroborando um firme interesse em uma operação envolvendo a combinação das empresas. 
A proposta constante na carta, para se promover a combinação de negócios das empresas, era por meio de uma reorganização societária (incluindo incorporação de ações). Em 01 de julho de 2016 a Kroton recebeu o aceite do Conselho de Administração da Estácio das bases financeiras da proposta revisada, enviada em 30 de junho de 2016. Transcreve-se, abaixo, conforme o fato relevante divulgado em 01 de julho de 2016, no site da B3, a proposta:

\begin{abstract}
De acordo com a referida proposta, a combinação da Kroton e Estácio resultaria: (a) na titularidade, pela Kroton, da totalidade das ações de emissão da Estácio; e (b) no recebimento, para cada ação ordinária de emissão da Estácio, de 1,281 ação ordinária de emissão da Kroton (considerando 307.680.459 ações de Estácio e 1.617.548.842 ações da Kroton, excluindo-se, em ambos os casos, as ações em tesouraria) e (c) na distribuição de dividendos extraordinários aos acionistas da Estácio no valor de R \$ 170.000.000,00 (cento e setenta milhões de reais), representando aproximadamente R \$ 0,55 por ação da Estácio. (Kroton, 2016)
\end{abstract}

Segundo o website Infomoney a operação estava avaliada em $\mathrm{R} \$ 5,5$ bilhões de reais. No entanto, ressaltava-se que a transação estaria sujeita à aprovação do CADE (Conselho Administrativo de Defesa Econômica), sendo essa entidade a responsável, no âmbito do poder Executivo, por decidir sobre esse tipo de matéria.

Um parecer emitido pela Superintendência-Geral do CADE em fevereiro de 2017 já havia apontado que o "ato de concentração oferece riscos à concorrência, e que não há eficiências específicas e verificáveis que possam ser repassadas ao consumidor" (CADE, 2017). Já em 28 de junho de 2017, há mais de um ano do primeiro fato, o processo de avaliação foi finalizado, quando por 5 votos a 1, o parecer do CADE foi de recusa à aprovação da combinação entre a Kroton e a Estácio. Ambas as instituições divulgaram fatos relevantes ao mercado na mesma data, informando que a operação de combinação se tornara sem efeito. Conforme noticiado pelo Valor Econômico à época, o parecer de recusa foi pautado na dimensão das duas empresas, a líder e a segunda colocada do mercado educacional. Dessa maneira, conforme a Folha de São Paulo, os conselheiros do CADE argumentaram que os ganhos de escala com a operação deixariam a nova companhia "grande demais". Ademais, os conselheiros não vislumbraram, também, a possibilidade de alcance dos remédios propostos pela relatora do caso.

\title{
2.5 Retornos Normal e Anormal
}

O retorno anormal é a diferença entre o retorno observado e o retorno esperado, ou retorno normal, do ativo. Camargos e Barbosa (2003) esclarecem que "o retorno normal é definido como o retorno esperado sem a condição de que o evento ocorra, enquanto o retorno anormal é definido como o retorno observado ex post de um título menos o retorno normal da firma na janela de evento":

$$
\mathrm{AR}_{\text {it }}=\mathrm{R}_{\mathrm{it}}-\mathrm{E}\left(\mathrm{R}_{\mathrm{it}} / \mathrm{X}_{\mathrm{t}}\right)
$$

onde $\mathrm{AR}_{\mathrm{it}}, \mathrm{R}_{\mathrm{it}}$ e $\mathrm{E}\left(\mathrm{R}_{\mathrm{it}} / \mathrm{X}_{\mathrm{t}}\right)$, são, respectivamente, o retorno anormal, retorno observado e retorno esperado do ativo i para o período $t$, com base nas informações de $X_{t}$, condicionantes do modelo de geração de retornos anormais. $\mathrm{E}$ o cálculo de $\mathrm{R}_{\mathrm{it}}$ pode ser realizado através do logaritmo da razão $\left(P_{t} / P_{t-1}\right)$, que são, respectivamente, o preço de fechamento da ação do período $t$ e $t-1$ (Soares, Rostagno, \& Soares, 2002; Camargos \& Barbosa, 2003).

Mackinlay (1997) enxerga duas categorias para classificação de quaisquer metodologias de cálculo do retorno normal: a estatística e a econômica. Modelos da primeira categoria adotam pressupostos estatísticos que envolvem o comportamento dos retornos dos ativos, de modo que, sejam independentes de quaisquer argumentos econômicos. A categoria dos modelos econômicos assume suposições relativas ao comportamento dos investidores, 
excepcionalmente. Para tanto, para cálculo dos retornos anormais, o presente estudo utilizouse dos modelos de Retornos Ajustados ao Mercado e Retornos Ajustados ao Risco e ao Mercado, classificados na categoria estatística.

\subsubsection{RETORNOS AJUSTADOS AO MERCADO}

Neste modelo, considera-se que o retorno esperado para qualquer ativo $i$, no momento $t$, é igual ao retorno esperado da carteira de mercado de risco naquele mesmo momento $t$, $E\left(\tilde{R}_{i t}\right)=E\left(\tilde{R}_{m}\right)$. Conforme Camargos e Barbosa (2003), os pressupostos são: os retornos esperados ex ante, são iguais, para todos os ativos, mas não necessariamente constantes ao longo do tempo; e, o retorno esperado ex ante de retorno de mercado é a média ponderada do volume financeiro negociado dos retornos das ações que a compõem. Dado essas condições, os retornos anormais são medidos conforme segue:

$$
A R_{i t}=R_{i t}-R_{m t}
$$

onde, $A R_{i t} \mathrm{e} R_{i t}$, são, respectivamente, o retorno anormal e o retorno real da ação $i$ no momento $t$, e $R_{m t}$ é o retorno do portfólio de mercado no mesmo momento $t$, considerado neste estudo pelo Índice da Bolsa de Valores Bovespa (Ibovespa).

\subsubsection{RETORNOS AJUSTADOS AO RISCO E AO MERCADO}

Este segundo modelo leva em consideração o risco específico de cada firma:

$$
R_{i t}=\alpha_{i}+\beta_{i} R_{m t}+\varepsilon_{u}
$$

na qual $E\left(\varepsilon_{u}\right)=0$

$$
R_{i t}=\alpha_{i}+\beta_{i} R_{m t}
$$

sendo, $R_{i t}$ o retorno real da ação $i, R_{m t}$ o retorno do portfólio de mercado (Ibovespa), e $\alpha_{i} \mathrm{e} \beta_{i}$ são os parâmetros estimados para a ação $i$, através do procedimento de regressão linear simples, e que Segundo Mckinlay (1997), deverão ser medidos fora da janela de evento. Assim, pelo modelo de Ajuste ao Risco e ao Mercado, o cálculo do retorno anormal dá-se pela seguinte equação:

$$
A R_{i t}=R_{i t}-\left(\alpha_{i}+\beta_{i} R_{m t}\right)
$$

Repassados os cálculos dos retornos, observou-se a necessidade de adaptação das fórmulas pelo procedimento trade-to-trade, "o qual despreza os dias sem negociação, utilizando somente as taxas de retorno efetivamente observadas" (Camargos \& Barbosa, 2003). Seguem as fórmulas adaptadas:

$$
\begin{gathered}
R_{i, n_{t}}=\ln \left(\frac{P_{i, n_{t}}}{P_{i, n\left(t-n_{t}\right)}}\right) \\
A R_{i, n_{t}}=R_{i, n_{t}}-R_{m, n_{t}} \\
A R_{i, n_{t}}=R_{i, n_{t}}-\left(\alpha_{i, n_{t}}+\beta_{i} R_{m, n_{t}}\right)
\end{gathered}
$$

onde:

$R_{i, n_{t}}=$ retorno observado da firma $i$

$P_{i, n_{t}}=$ preço da ação da firma $i$, no dia $t$ posterior ao intervalo $i$ ocorrido desde a última negociação 
$P_{i, n\left(t-n_{t}\right)}=$ preço da ação $i$, no dia $t$ posterior ao intervalo $i$ ocorrido desde a última negociação

$A R_{i, n_{t}}=$ retornos anormais da firma $\mathrm{i}$, no dia $\mathrm{t}$, com $\mathrm{n}$ dias decorridos desde a última negociação

$R_{m, n_{t}}=$ retorno do Ibovespa correspondente aos dias em que a ação da firma $i$ foi negociada com $n$ dias decorridos desde a última negociação

$\alpha_{i, n_{t}} \mathrm{e} \beta_{i}=$ parâmetros estimados da firma $i$

$\mathrm{n}_{\mathrm{t}}=$ intervalo de tempo decorrido desde a última negociação.

O uso deste modelo pressupõe normalidade conjunta dos retornos dos ativos, linearidade, estacionaridade, independência dos resíduos em relação ao retorno de mercado e estabilidade da variância dos resíduos. Todos os testes estatísticos e tratamento das séries foram realizados nos softwares estatísticos Stata $^{\circledR}$ e Action $^{\circledR}$.

\subsubsection{ACUMULAÇÃO DOS RETORNOS ANORMAIS}

Conforme Mckinlay (1997), as observações de retorno anormal devem ser agregadas, a fim de chamar as inferências globais para o evento de interesse, a agregação pode ocorrer através do tempo e dos títulos.

No primeiro momento, trata-se da agregação através do tempo, com a técnica do Retorno Anormal Acumulado, ou CAR, expresso pela fórmula:

$$
\operatorname{CAR}_{t}\left(t_{1}, t_{2}\right)=\sum_{t=t_{1}}^{t_{2}} A R_{i t}
$$

Onde o retorno anormal acumulado de $t_{1}$ e $t_{2}$ está no intervalo $T_{1}<t_{1} \leq t_{2} \leq T_{2}$.

A agregação através dos títulos dá-se pelo modelo:

$$
\overline{A R}_{t}=\frac{1}{N} \sum_{t=t_{1}}^{N} A R_{i t}
$$

A análise dos retornos anormais é realizada após estimativa dos retornos anormais acumulados.

\section{METODOLOGIA}

Para avaliação dos fatos relevantes e seus efeitos decorrentes dos eventos da combinação de negócios entre a Kroton e a Estácio, na performance dos preços das ações destas empresas, foi utilizada a metodologia do Estudo de Eventos. Segundo Mackinlay (1997), tal metodologia permite a medição do impacto de um evento específico sobre o valor de uma empresa (o valor de sua ação).

Conforme listado por Campbell, Lo e Mackinlay (1997), em linhas gerais, a técnica compreende os seguintes passos: (1) definição do evento de interesse e identificação do período em que as variáveis envolvidas no estudo serão examinadas; (2) determinação dos critérios de seleção para inclusão de uma determinada amostra no estudo; (3) definição da medida de retorno anormal; (4) procedimento de estimação; (5) procedimento de teste; (6) resultados empíricos, estes, normalmente seguem a formulação de desenho econométrico; e (7) interpretação e conclusões. 
A fim de capturar o efeito dos eventos nos preços dos títulos das empresas, calculou-se a medida de retorno anormal em conformidade com Camargos e Barbosa (2003).

\subsection{Evento e Amostragem}

A proposta do trabalho foi de analisar os dois eventos extremos do processo da potencial combinação de negócios das empresas: i) o primeiro fato relevante divulgado ao mercado - o anúncio; e ii) o parecer oficial negativo do CADE, comunicados por meio de fatos relevantes. Os eventos foram avaliados em ambas as empresas envolvidas, separadamente, com a justificativa de se analisar o impacto nas ações das companhias dos dois lados da transação. Ao longo do trabalho os eventos foram denominados de "Evento I" e "Evento II", respectivamente.

Fatos, ou atos, relevantes são informes oficiais das companhias abertas que espera-se revelar toda e qualquer decisão empresarial de caráter político-administrativo, técnico, negocial ou econômico-financeiro, que irão afetar o valor dos papéis dessas companhias e influenciar as decisões de compra e venda dos investidores. Os fatos aqui analisados foram os divulgados à B3 pela Kroton e Estácio.

Neste estudo, as janelas dos eventos são diárias e foram arbitradas pelos autores buscando conformidade com metodologias de outros estudos realizados. A data do evento, ou data zero, foi definida como a data da divulgação dos fatos relevantes - descritos na seção anterior -, e ao redor da data zero, foram consideradas 10 observações antes e depois $\left(t_{-10}\right.$ até $t_{+10}$ ) para compor a janela de evento; 90 observações antes à janela de evento para a janela de estimação $\left(t_{-11}\right.$ até $\left.t_{-100}\right)$; e 50 para a janela de comparação $\left(t_{+11}\right.$ até $\left.t_{+60}\right)$.

Os dados das cotações e do volume de negociação dos papéis foram coletados no acervo da B3 e no próprio site institucional das empresas. Na Tabela 3, estão algumas das características descritivas das séries de dados, com destaque para alguns coeficientes de variação acima de $30 \%$ de algumas séries.

Tabela 3. Caraterísticas das séries de dados da amostra

\begin{tabular}{lccccccc}
\hline \multicolumn{1}{c}{ Empresa } & Código & Evento & Média & Mínimo & Máximo & $\begin{array}{c}\text { Desvio } \\
\text { Padrão }\end{array}$ & $\begin{array}{c}\text { Coeficiente de } \\
\text { variação }\end{array}$ \\
\hline IBOVESPA & IBOV & Evento I & $0,20 \%$ & $-4,99 \%$ & $6,39 \%$ & 0,0208 & $10,4 \%$ \\
ESTÁCIO PARTICIPAÇÕES S.A. & ESTC3 & Evento I & $-0,10 \%$ & $-10,54 \%$ & $9,58 \%$ & 0,0367 & $-36,7 \%$ \\
KROTON EDUCACIONAL S.A. & KROT3 & Evento I & $0,21 \%$ & $-5,77 \%$ & $8,21 \%$ & 0,0303 & $14,4 \%$ \\
IBOVESPA & IBOV & Evento II & $-0,05 \%$ & $-9,21 \%$ & $2,37 \%$ & 0,0148 & $-29,6 \%$ \\
ESTÁCIO PARTICIPAÇÕES S.A. & ESTC3 & Evento II & $0,04 \%$ & $-13,70 \%$ & $8,56 \%$ & 0,0299 & $74,8 \%$ \\
KROTON EDUCACIONAL S.A. & KROT3 & Evento II & $0,04 \%$ & $-8,60 \%$ & $4,88 \%$ & 0,02 & $50,0 \%$ \\
\hline
\end{tabular}

\section{ANÁLISE E DISCUSSÃO DOS RESULTADOS}

Nesta seção, serão expostos, de forma sistematizada, os resultados obtidos pela execução da metodologia do estudo.

Dados os pressupostos, os resultados dos testes estatísticos - teste de linearidade (Coeficiente de Pearson), de autocorrelação dos resíduos (Durbin-Watson) e de significância dos coeficientes betas das regressões - obtidos para as quatro séries de observações das empresas, estão resumidos na Tabela 4. Não houve evidências para rejeição das hipóteses dos testes. Todas as séries apresentaram coeficiente de correlação Pearson e coeficiente de regressão à significância estatística de $1 \%$. Em relação ao valor do teste de Durbin-Watson, todas as séries apresentaram valores superiores ao limite inferior $(\mathrm{dL}=1,758)$ indicado para nível de significância estatística igual de 5\% a $10 \%$. 
Tabela 4. Resumo dos testes estatísticos das séries semanais

\begin{tabular}{|c|c|c|c|c|c|}
\hline Empresa & Código & Evento & $\begin{array}{l}\text { Coeficiente de } \\
\text { Pearson (Beta) }\end{array}$ & $\begin{array}{l}\text { Durbin- } \\
\text { Watson }\end{array}$ & $\begin{array}{c}\text { Coeficiente } \\
\text { Regressão }\end{array}$ \\
\hline ESTÁCIO PARTICIPAÇÕES S.A. & ESTC3 & Evento I & 0,5256 & 2,0470 & 0,9351 \\
\hline KROTON EDUCACIONAL S.A. & KROT3 & Evento I & 0,5852 & 2,0736 & 0,8536 \\
\hline ESTÁCIO PARTICIPAÇÕES S.A. & ESTC3 & Evento II & 0,6054 & 2,4587 & 1,2216 \\
\hline KROTON EDUCACIONAL S.A. & KROT3 & Evento II & 0,6155 & 2,2717 & 0,8310 \\
\hline
\end{tabular}

\subsection{Resultados dos Retornos Anormais - Evento I}

A Figura 1 representa os retornos anormais acumulados na janela de eventos do Evento I, o primeiro anúncio da combinação, calculados pelos modelos de Ajuste ao Mercado e de Ajuste ao Risco e ao Mercado. Observa-se que o retorno anormal significativo foi bastante pontual na data da divulgação do evento $t_{0}$, chegando a $33 \%$, composto pelos retornos anormais aproximados de $21 \%$ e $12,5 \%$, respectivamente, para as ações da Estácio e da Kroton, conforme pode ser visualizado nas Figuras 2 e 3.

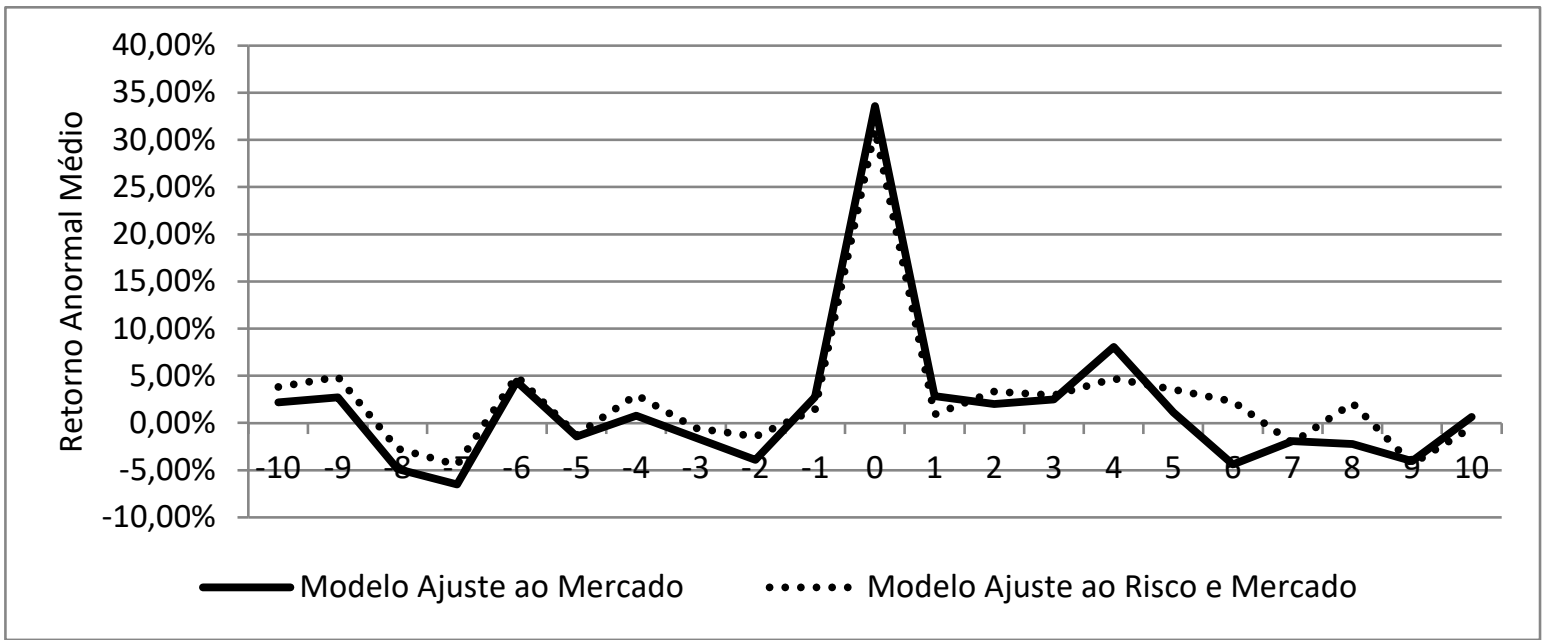

Figura 1. Retornos anormais acumulados na janela de eventos do Evento I

Os retornos anormais maiores para a Estácio, podem ser reflexo da oferta da Kroton, aceita por unanimidade do Conselho de Administração da Estácio, que incluiu troca de 1,281 ação de sua emissão para cada papel da Estácio e distribuição de dividendos extraordinários aos acionistas da Estácio, no valor de R \$ 420 milhões. 


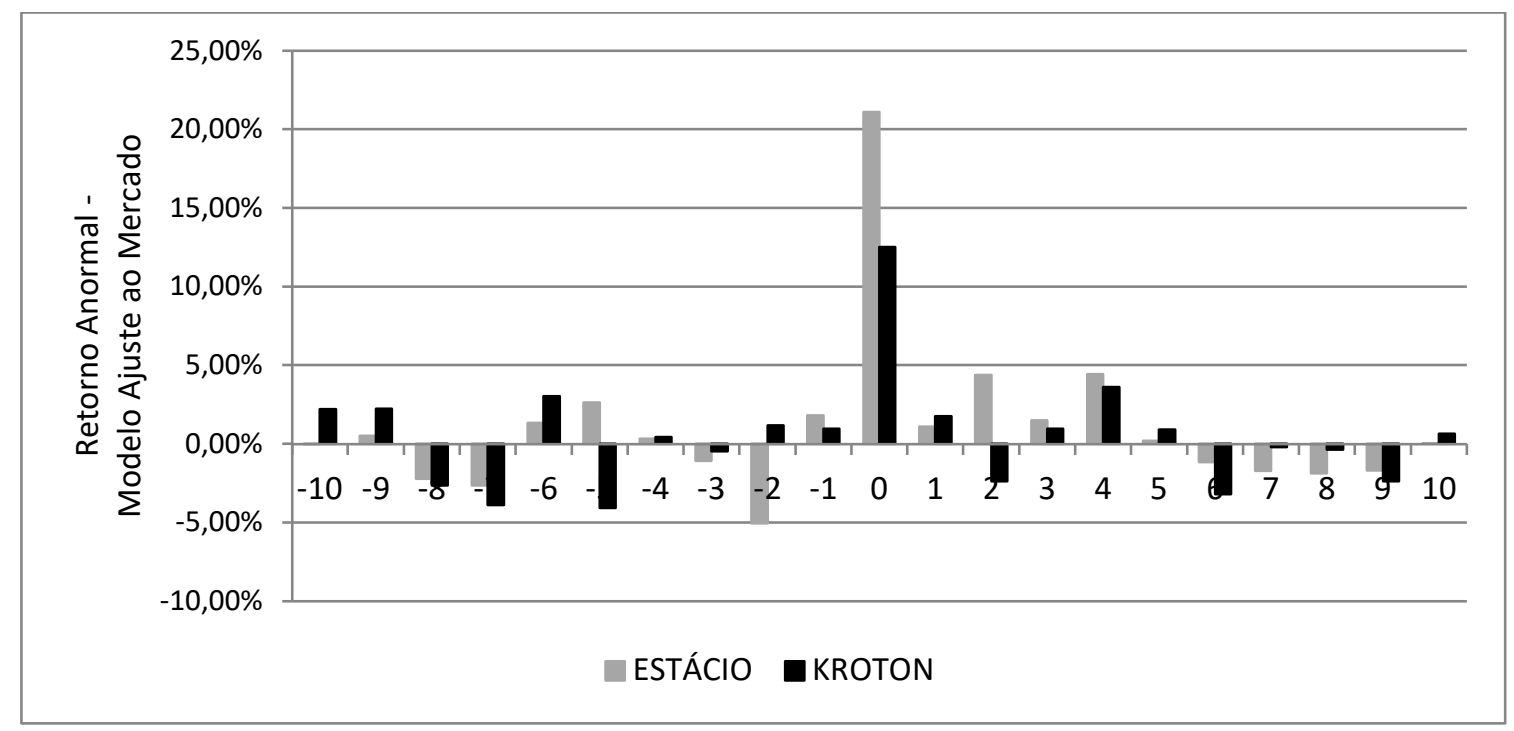

Figura 2. Retornos anormais modelo ajuste ao mercado na janela de eventos do Evento I

Ainda dentro da janela deste evento, os retornos anormais para os demais períodos variaram positivo e negativamente, sem qualquer oscilação expressiva. Contudo, no exercício da exclusão do retorno anormal do período $t_{0}$, por exemplo, o resultado da acumulação dos retornos anormais chegaria a apenas $1 \%$ durante o período, indicando que os investidores não conseguiram alcançar consistentes e positivos retornos superiores à média do mercado - igual resultado foi obtido com o modelo dos retornos ajustados ao Risco e ao Mercado.

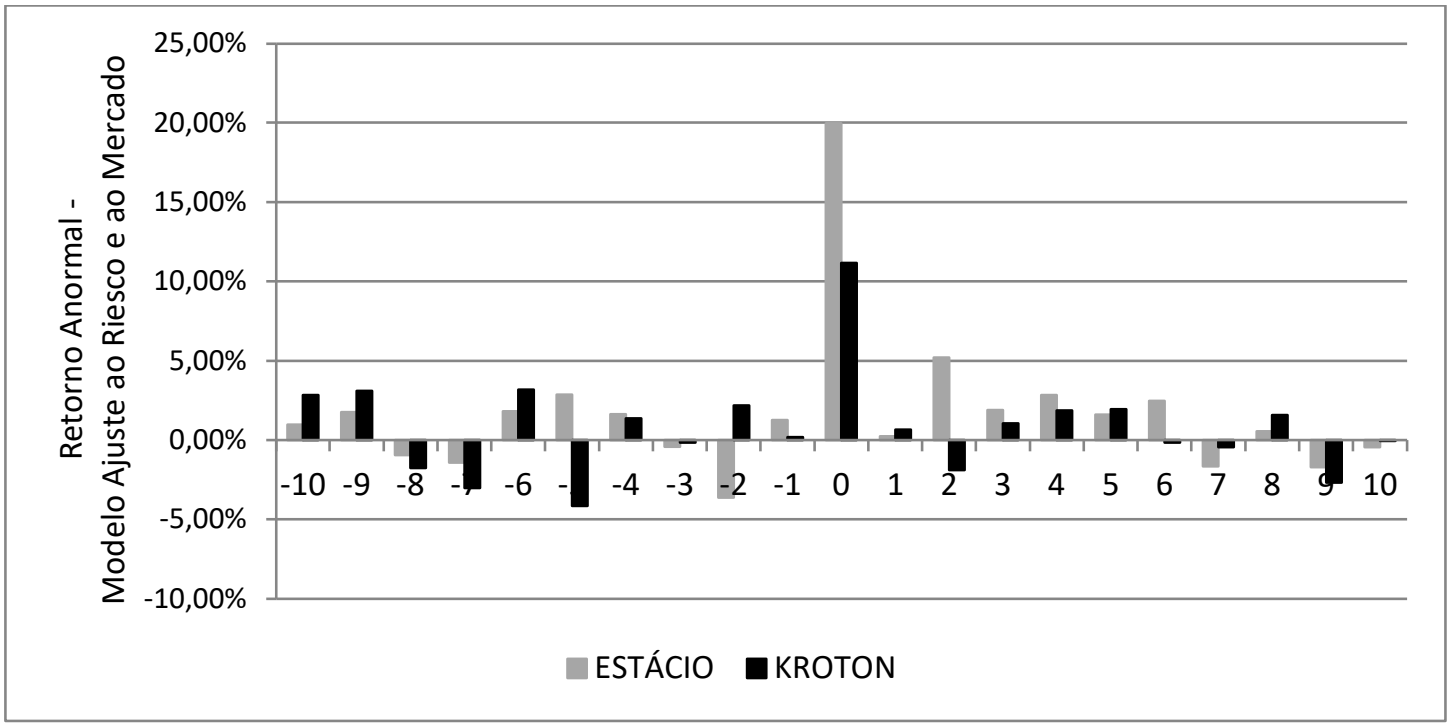

Figura 3. Retornos anormais modelo ajuste ao risco e mercado na janela de eventos do Evento I

Na Figura 4, nota-se que o Modelo do Ajuste ao Risco e Mercado precifica em termos absolutos maiores retornos anormais acumulados durante a janela de estudo. 


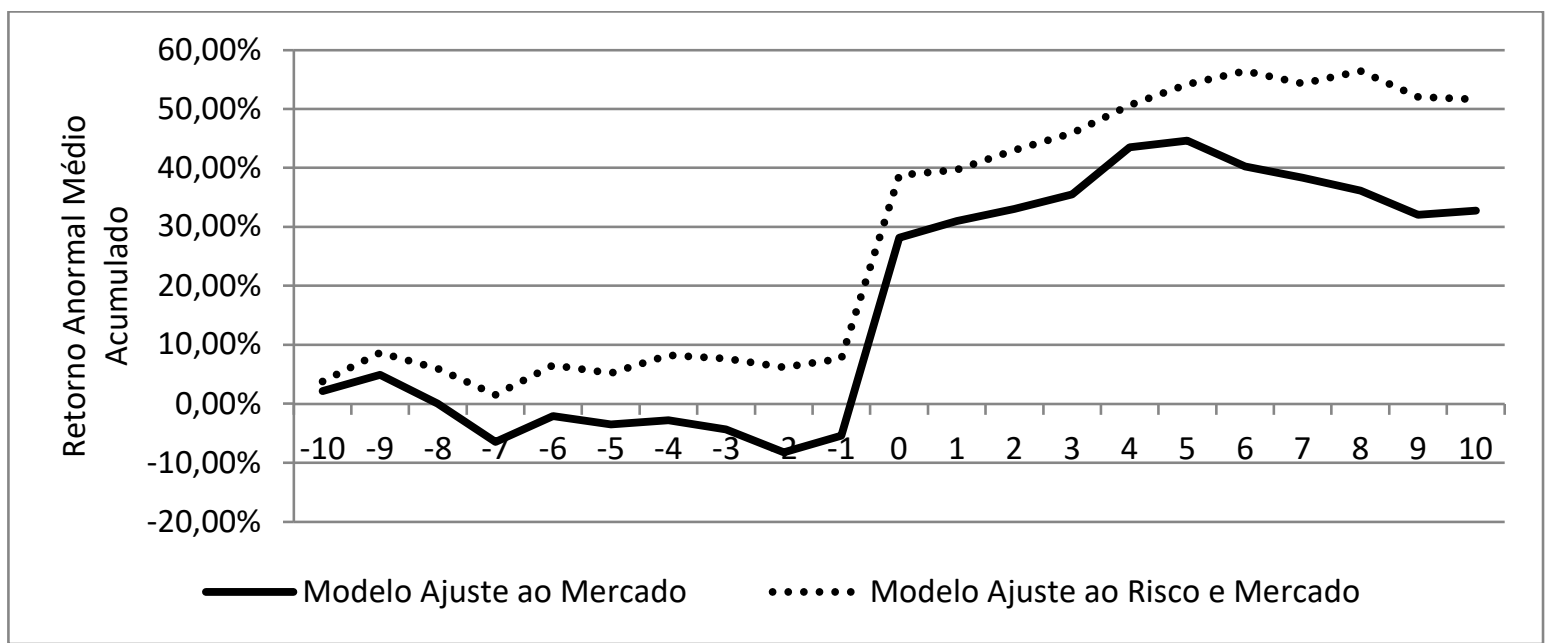

Figura 4. Acumulação dos retornos anormais na janela de eventos do Evento I

\subsection{Resultados dos Retornos Anormais - Evento II}

$\mathrm{Na}$ janela de eventos do Evento II, o anúncio da negativa do CADE, os retornos anormais acumulados reagiram com oscilações positivas e negativas, e com alguns picos maiores em momentos ex ante ao evento (representados nas Figuras 5 a 7). Em $\mathrm{t}_{-6}$ os retornos acumulados que ainda não demonstravam grandes oscilações, caíram $10 \%$, recuperando o patamar de $6 \% \mathrm{em} \mathrm{t}_{-4}$, e caindo $7 \%$ um dia antes ao evento. Em $\mathrm{t}_{0}$, o retorno anormal foi aproximadamente de 5\%, sendo, - 0,5\% e 5,5\%, respectivamente, para as ações da Estácio e da Kroton, como demonstrado nas Figuras 6 e 7.

Essas oscilações podem ser o reflexo das especulações dos investidores, diante a expectativas divididas entre a negativa ou a aprovação do CADE. Sendo a primeira sustentada pelos prenúncios de preocupação desse Conselho, e a segunda nutrida pela esperança de um desfecho semelhante àquele da combinação Kroton-Anhanguera Educacional, em 2013, que também foi um processo considerado complexo pelo Conselho, mas aprovado com algumas exigências - venda de uma unidade de Educação Continuada da Kroton.

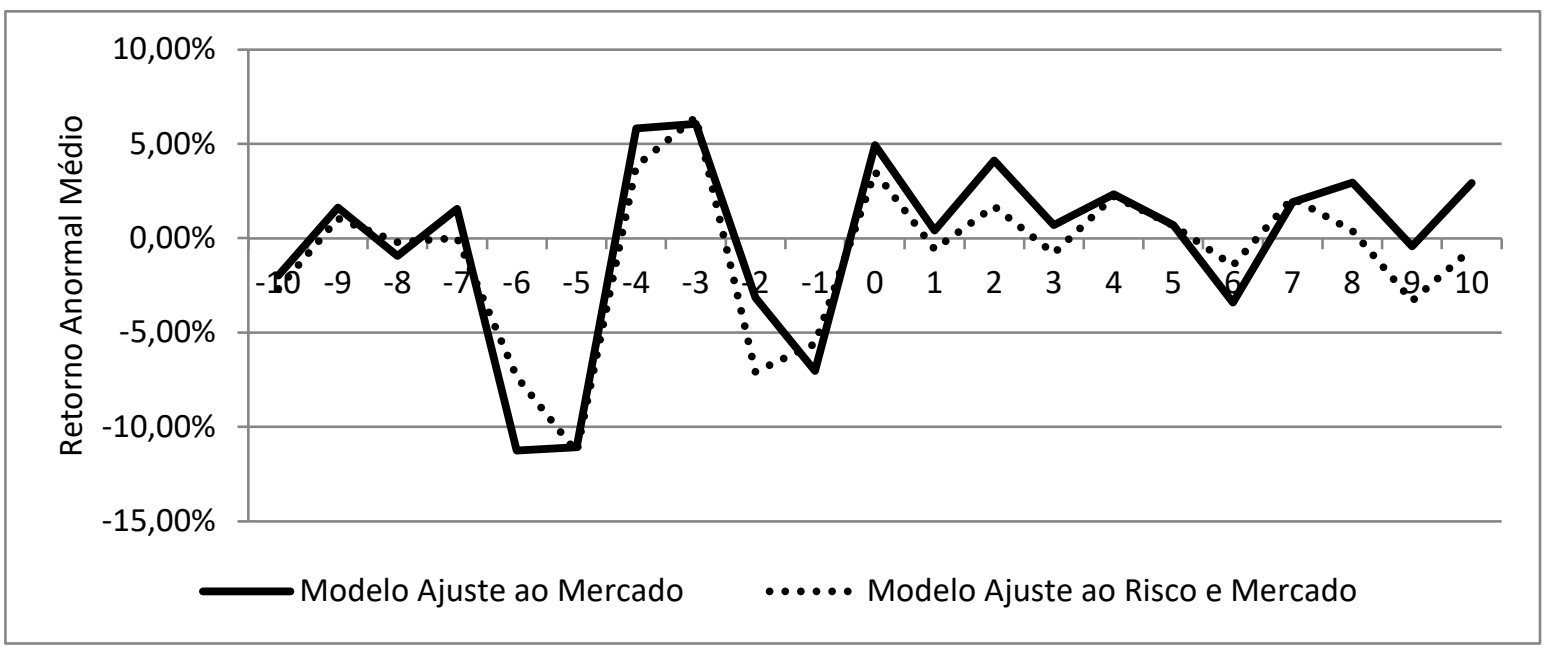

Figura 5. Retornos anormais acumulados na janela de eventos do Evento II 


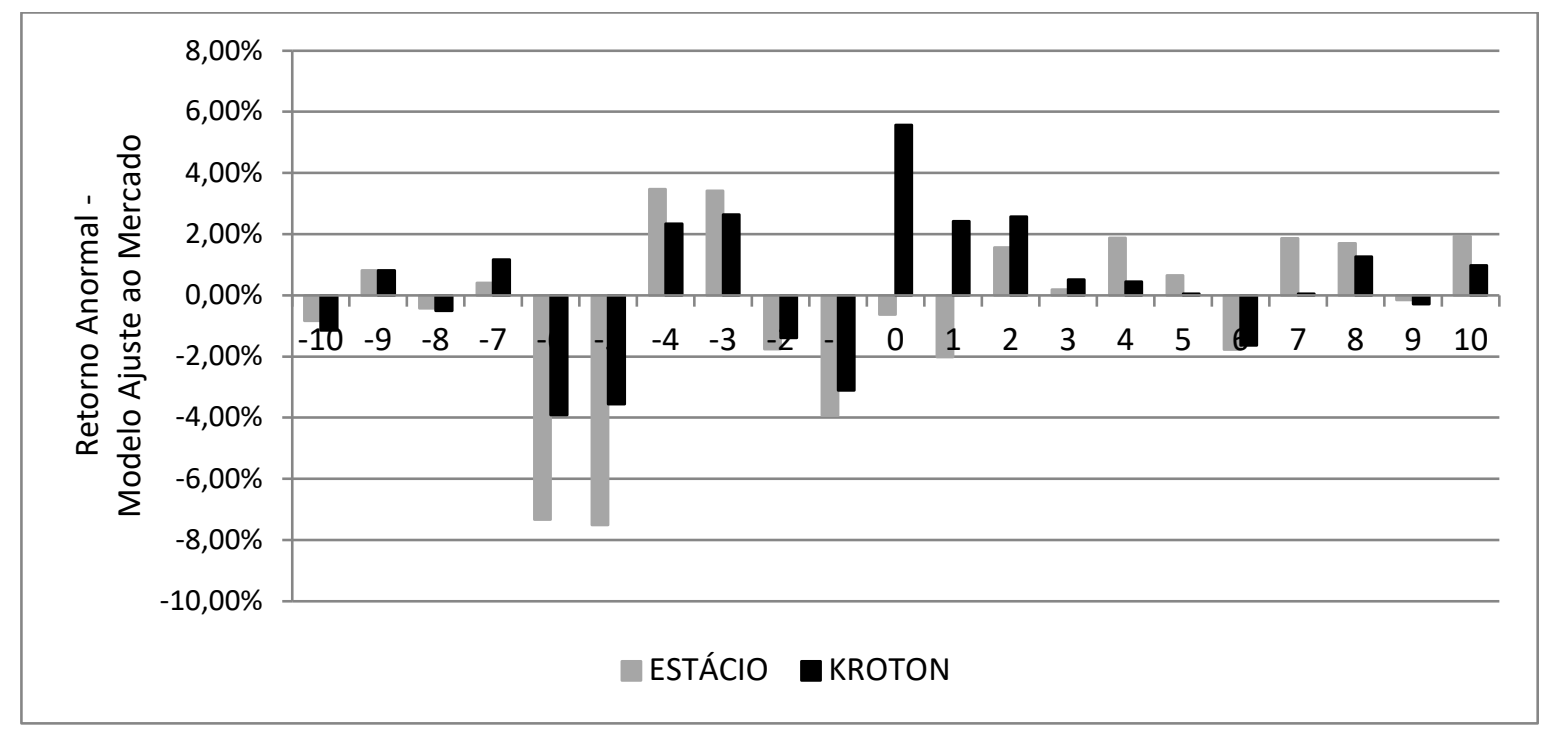

Figura 6. Retornos anormais modelo ajuste ao mercado na janela de eventos do Evento II

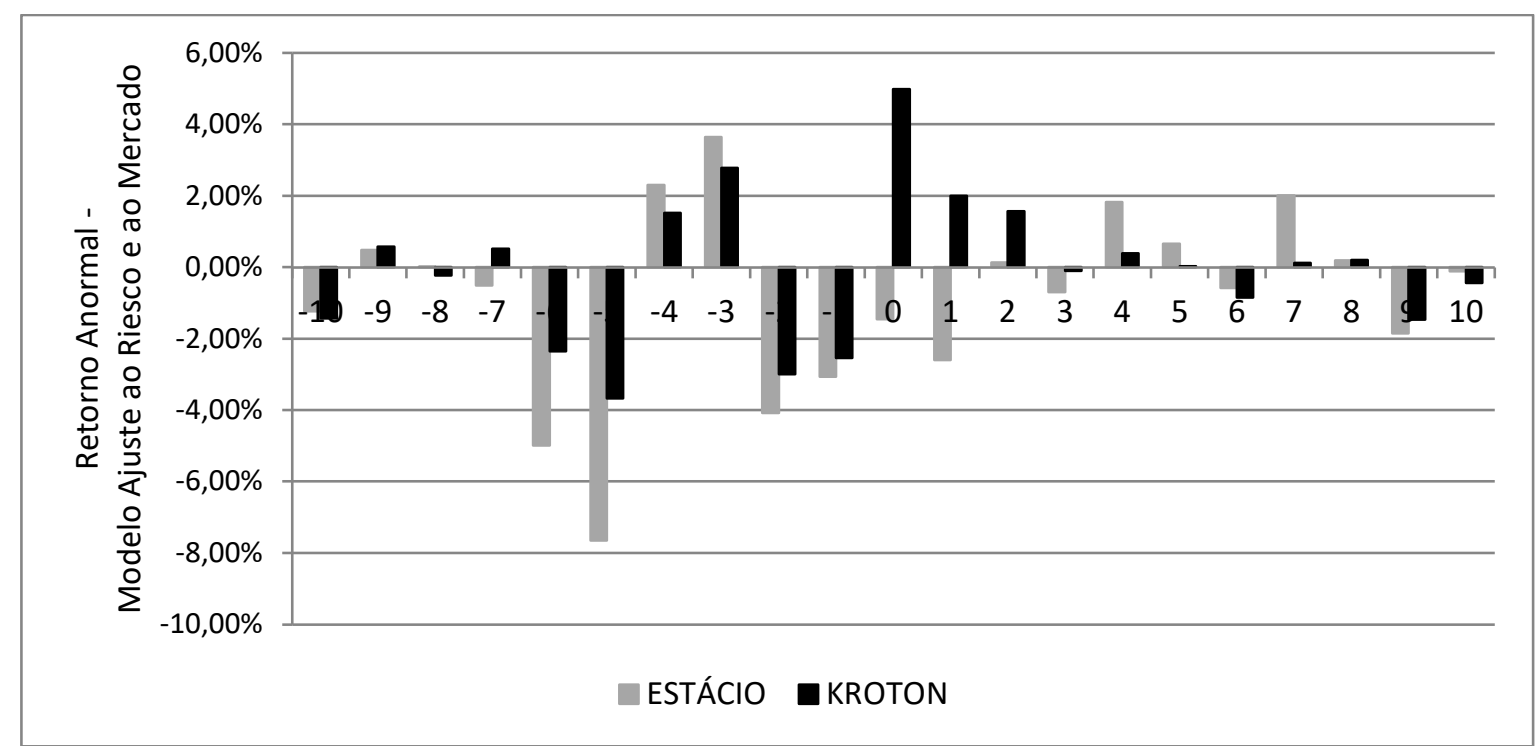

Figura 7. Retornos anormais modelo ajuste ao risco e mercado na janela de eventos do Evento II

Mesmo os retornos mantendo-se em uma faixa positiva após $t_{0}$, com exceção ao período $t_{6}$, acumuladamente, a janela de evento reproduziu retornos anormais negativos conforme demonstrado na Figura 8, mas com expectativa de retornar aos valores positivos, considerandose o modelo de ajuste ao Mercado.

Os retornos negativos foram maiores para a Estácio, contrapondo os retornos anormais positivos do evento I para estes acionistas, que seriam beneficiados com dividendos extraordinários ofertados pela Kroton para a combinação. 


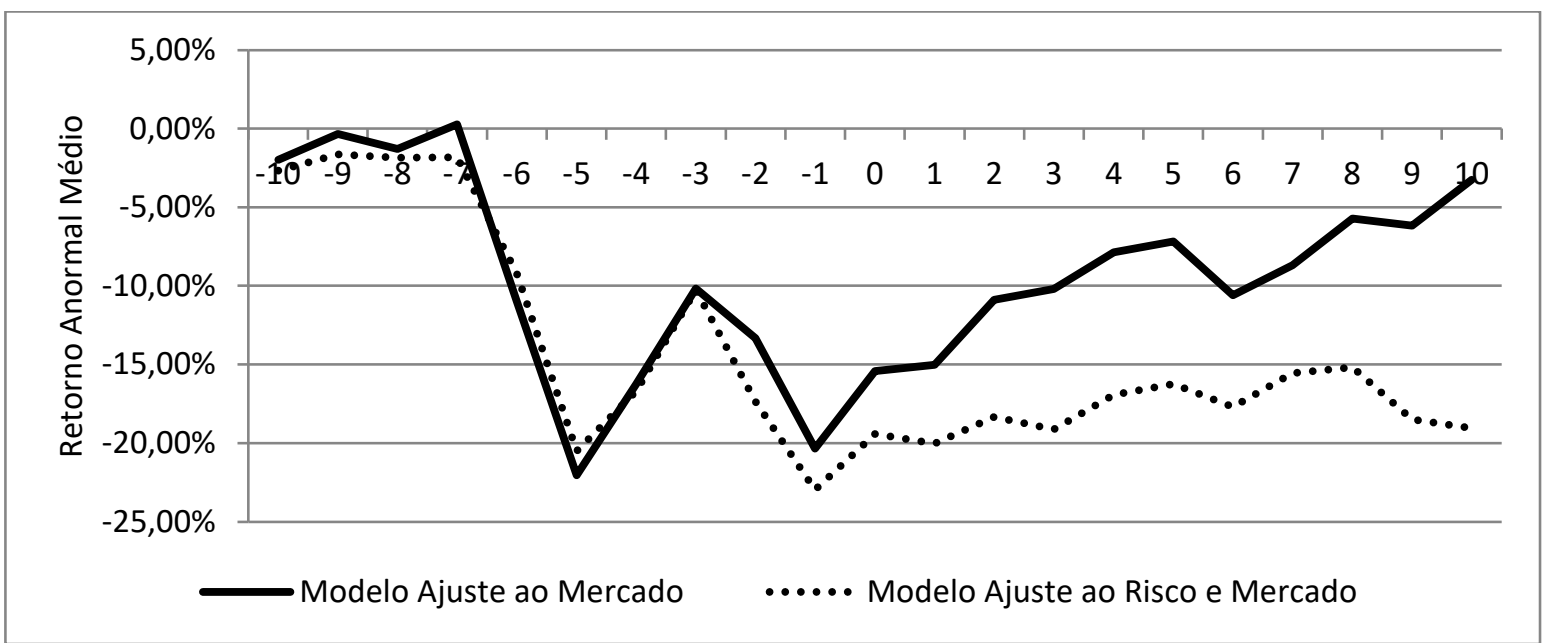

Figura 8. Acumulação dos retornos anormais na janela de eventos do Evento II

Em acordo com o constatado no tópico anterior, o Modelo do Ajuste ao Risco e Mercado precifica, em termos absolutos, maiores retornos anormais acumulados dentro da janela de estudo.

\section{CONSIDERAÇÕES FINAIS}

Com o objetivo de analisar o impacto de dois importantes eventos no caso da potencial combinação de negócios entre a Estácio e a Kroton, avaliou-se através das oscilações nos preços das ações destas empresas pela metodologia do estudo de eventos, a geração de retornos anormais em janelas de eventos diárias. Foram dois os métodos utilizados para cálculo dos Retornos Anormais: Retornos Anormais Ajustados ao Mercado e Retornos Anormais Ajustados ao Risco e ao Mercado.

Para o Evento I: o primeiro fato relevante divulgado ao mercado - o anúncio da potencial combinação de negócios, observa-se um pico representativo e singular na data $t_{0}$, chegando o retorno anormal acumulado ao patamar de $33 \%$, composto por $21 \%$ e $12,5 \%$, respectivamente, para as ações da Estácio e da Kroton. Em termos da acumulação dos retornos, a janela de evento gerou retornos anormais acumulados em 32\% para o Modelo de Ajuste ao Mercado e 51\% para o Ajustado ao Risco e Mercado. Ressalta-se que, no exercício da exclusão do retorno anormal do período $t_{0}$, por exemplo, os resultados dessa acumulação não seriam representativos durante o período, indicando que os investidores não conseguiram alcançar consistentes e positivos retornos superiores à média do mercado.

Para o Evento II: o parecer negativo do CADE, os retornos anormais dentro da janela de evento oscilaram entre retornos negativos com o mínimo de $-11 \%$ em $t_{-6}$ e positivos, com o máximo de $6 \%$ em $t_{-3}$. Após a data do evento $t_{0}$, com exceção ao momento $t_{6}$, os resultados demonstraram retornos anormais positivos, porém não foram suficientes para garantir o ganho do investidor neste período, sendo os valores acumulados de $-3,25 \%$ para o Modelo de Ajuste ao Mercado e $-19,05 \%$ para o Ajustado ao Risco e Mercado.

Finalmente, conclui-se que os retornos anormais acumulados foram representativos para o Evento I, gerando ganho ao investidor que manteve ações das empresas no período da divulgação da potencial combinação de negócios. Os retornos anormais maiores para a Estácio podem ser reflexo da oferta da Kroton, aceita por unanimidade pelo Conselho de Administração da Estácio, que incluía a troca de 1,281 ação de sua emissão para cada papel da Estácio e a distribuição de dividendos extraordinários aos acionistas da Estácio, no valor de R \$420 milhões. 
Entretanto, os retornos acumulados para o Evento II foram negativos e seus valores não tão expressivos, demonstrando que talvez o mercado já houvesse precificado o evento anteriormente à janela do evento. As oscilações de períodos antes do evento podem ser o reflexo de especulações no mercado, uma vez que havia expectativas positivas e negativas em relação à aprovação do CADE - o próprio Conselho sinalizara suas preocupações com a concentração, mas em caso anterior semelhante (Kroton e Anhanguera Educacional, em 2013), aprovou a operação, impondo exigências, como venda de unidade produtiva da Kroton. Neste contexto, as variações não podem ser tratadas, exclusivamente, em função de algum elemento interno da operação das empresas (a esperada sinergia), mas podem ser compreendidas como o efeito da incerteza provocada pela não tempestiva manifestação do CADE, possibilitando a geração de uma "aposta" positiva ou negativa.

Os retornos negativos foram mais impactantes para a Estácio, contrapondo aos retornos anormais positivos do evento I para estes acionistas, que seriam beneficiados com dividendos extraordinários ofertados pela Kroton para combinação.

Assim, pode-se inferir que não houve vencedores ou perdedores nesta operação, uma vez que alguns elementos não estavam tão bem mapeados por todos os investidores (mercado), mas que não pode levar a uma análise de ineficiência de mercado; ao contrário, pode-se inferir que o mercado enxergou o que foi possível e precificou conforme expectativas difusas de seus participantes. Talvez seja uma indicação para aprimoramento de estudos de avaliação em casos deste tipo.

\section{REFERENCIAS}

B3. (2020). Empresas Listadas. 2020. Recuperado de http://www.b3.com.br.

Brealey, R. A., \& Myers, S. C. (1995). Princípios de finanças empresariais (3a ed.) Lisboa: McGrawHill.

Camargos, M. A., \& Barbosa, F. D. (2003). Estudos de evento: teoria e operacionalização. Caderno de Pesquisas em Administração, 10(3), 01-20.

Camargos, M. A., \& Barbosa, F. D. (2003). Teoria e evidência da eficiência informacional do mercado de capitais brasileiro. Caderno de Pesquisas em Administração, 10(1), 41-55.

Camargos, M. A., \& Barbosa, F. D. (2005). Análise do desempenho econômico-financeiro e da criação de sinergias em processos de fusão e aquisição do mercado brasileiro ocorrido entre 1995 e 1999. Caderno de Pesquisas em Administração, 12(2), 99-115.

Camargos, M. A., \& Barbosa, F. D. (2015). Eficiência informacional do mercado de capitais brasileiro em anúncios de fusões e aquisições. Production, 25(3), 571-584.

Campbell, J. Y., Lo, A. W., \& Mackinlay, A. C. (1997). The econometrics of financial markets (2a ed.). New Jersey: Princeton University Press.

Calil, M. R., Bueno, J. M., Domingues, C. R., \& Borges, J. F. (2020). Revisão bibliométrica sobre fusão e aquisição de empresas no Brasil. Revista Ibero-Americana de Estratégia, 19(4), 76-99. 
Estadão. (2017). Ministro da Educação culpa crise econômica por estagnação de matrículas no ensino superior. Recuperado de http://educacao.estadao.com.br/noticias/geral,ministroda-educacao-culpa-crise-economica-por-estagnacao-de-matriculas-noensinosuperior,70001959011.

Eloy, J. C. C., \& Souza, M. M. (2018). Reconhecimento dos ativos intangíveis nas combinações de negócios: uma análise nas características das companhias de capital aberto brasileiras no período entre 2012 e 2014. Revista de Contabilidade da UFBA, 12(1), 116-136.

Fasolin, L. B., Brizolla, M. M. B., Silva, A. da, \& Klann, R. C. (2019). Características de companhias: práticas de combinação de negócios. $R C \& C$ - Revista Contabilidade $e$ Controladoria, 11(2), 8-23.

Fogaça, F. M., Souza, B. S., Oliveira, W. S., \& Silva, J. R. (2020). Nível da divulgação dos ativos identificáveis reconhecidos em uma combinação de negócios. Revista Liceu On-line, 10(1), 96-112.

Gitman, L. J. (2004) Princípios da Administração Financeira (10a ed.). São Paulo: Pearson Addison Wesley.

Infomoney. (2013). As 6 aquisições que tornaram a Kroton a maior empresa de educação do mundo. Recuperado de http://www.infomoney.com.br/kroton/noticia/2742805/aquisicoesque-tornaram-kroton-maior-empresa-educacao-mundo.

Infomoney. (2017). Fusão Kroton/Estácio: o "final de uma novela” que dará origem a 3 novas "minisséries" no setor de educação. Recuperado de https://www.infomoney.com.br/colunistas/thiago-salomao/fusao-kroton-estacio-o-finalde-uma-novela-que-dara-origem-a-3-novas-minisseries-no-setor-deeducacao/\#: :text=Fus\%C3\%A3o\%20Kroton\%2FEst\%C3\%A1cio\%3A\%20o\%20\%E2\% 80\%9C,miniss\%C3\%A9ries\%E2\%80\%9D\%20no\%20setor\%20de\%20educa\%C3\%A7\% C3\%A3o\&text=S\%C3\%83O\%20PAULO $\% 20 \% \mathrm{E} 2 \% 80 \% 93 \% 20 \mathrm{Uma} \% 20$ das\%20maiore s,quarta\%2Dfeira\%20(28).

Gelbcke, E. R., Santos, A. D., Iudícibus, S. de, \& Martins, E. (2021). Manual de contabilidade societária (3a ed.). São Paulo: Atlas.

KROTON (Kroton Educacional S.A.). (2017). Site da Empresa. Recuperado de http://www.kroton.com.br/.

Mackinlay, A. C. (1997). Event studies in economics and finance. Journal of Economic Literature, Nashville: American Economic Association, 35(1), 13-39.

Macohon, E. R., Zittei, M. V. M., \& Klann, R. C. (2016). Análise da variância dos indicadores de desempenho das empresas que passaram por operações de combinação de negócios. Contextus - Revista Contemporânea de Economia e Gestão, 14(2), 199-211.

Martelanc, R., Passin, R., \& Pereira, F. (2010). Avaliação das empresas: um guia para fusões \& aquisições e privaty. São Paulo: Pearson Prentice Hall. 
Melo, I. C. A., Tinoco, J. E. P., \& Yoshitake, M. (2012). Combinação de negócios no Brasil em empresas de capital aberto no período de 2005 a 2008: identificação dos impactos nas demonstrações financeiras. Revista da Faculdade de Administração e Economia, 4(1),2346.

Nakayama, W. K. (2012). Divulgação de informações sobre operações de combinação de negócios na vigência do Pronunciamento Técnico CPC 15 (Dissertação de Mestrado). Universidade de São Paulo, São Paulo, 2012.

Silva, D. G., Souza, G. H. D., Avelino, B. C., \& Pinheiro, L. E. T. (2020). Perda por redução ao valor recuperável do goodwill: value relevance em empresas listadas na B3. Revista de Contabilidade do Mestrado em Ciências Contábeis da UERJ, 25(2), 141-157.

Soares, R.O., Rostagno, L.M., \& Soares, K.T.C. (2002, set). Estudo de evento: o método e as formas de cálculo do retorno anormal. Anais do Encontro da Associação Nacional de PósGraduação e Pesquisa em Administração (Anpad), Salvador, BA, 20.

Toigo, L. A., Hein, N., \& Kroenke, A. (2018). Características predominantes dos mecanismos de governança corporativa e desempenho pós-fusões e aquisições no Brasil. Enfoque: Reflexão Contábil, 37(4), 85-104.

Valor Econômico. (2017). CADE veta fusão entre Kroton e Estácio por 5 votos a 1. Recuperado de http://www.valor.com.br/empresas/5020266/cade-veta-fusao-entre-kroton-e-estaciopor-5-votos-1.

Valor Econômico. (2021). Ranking 1000 Maiores. Recuperado de https://especial.valor.com.br/valor1000/2016/ranking1000maiores/Educa\%C3\%A7\%C3 \%A3o_e_Ensino.

Vieira, L. B., Brito, S. S., Santana, J. R. B., Sanches, S. L. R., \& Galdamez, E. V. C. (2017). Reflexo das operações de fusões e aquisições nos indicadores financeiros das empresas brasileiras de capital aberto. Revista de Gestão, 24(3), 235-246. 